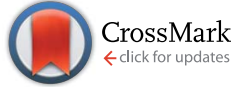

Cite this: RSC Adv., 2014, 4, 34412

\title{
Diguanidinocalix[4]arenes as effective and selective catalysts of the cleavage of diribonucleoside monophosphates $\dagger$
}

\author{
Riccardo Salvio, ${ }^{\text {a }}$ Roberta Cacciapaglia, ${ }^{a}$ Luigi Mandolini, ${ }^{a}$ Francesco Sansone ${ }^{b}$ \\ and Alessandro Casnati ${ }^{\mathrm{b}}$
}

Received 14th June 2014

Accepted 24th July 2014

DOI: $10.1039 / c 4 r a 05751 a$

www.rsc.org/advances

\begin{abstract}
Calix[4]arenes derivatives 1 and 2, featuring two guanidine units at the upper rim, catalyze the transesterification of diribonucleoside monophosphates much more effectively than that of HPNP. Rate accelerations relative to the background range from $10^{3}$ to $10^{4}$-fold, and approach $10^{5}$-fold with the most favorable substrate-catalyst combinations.
\end{abstract}

\section{Introduction}

The inertness of phosphodiesters towards hydrolysis ${ }^{1}$ has challenged many research groups to the design of artificial phosphodiesterases ${ }^{2-6}$ with the purpose of achieving efficient and selective cleavage of polynucleotides and polyribonucleotides. The potential application of these enzyme mimics to health related goals is an attractive target of investigation in this field. ${ }^{7}$

Metal cations, notably copper(II) and zinc(II), are at the core of most artificial phosphodiesterases, ${ }^{2}$ but nonmetallic active units as well have received some attention..$^{2 p, 3-6}$ In a recent work $^{5}$ we found that upper rim diguanidino-cone-calix [4]arenes 1 and 2 catalyze the cleavage of the RNA model compound 2-hydroxypropyl-p-nitrophenyl phosphate (HPNP). It was shown that the catalysts are active in their protonated forms $1 \mathrm{H}^{+}$and $2 \mathrm{H}^{+}$, in which the guanidineguanidinium dyad combines the general base action of the neutral guanidine with the electrophilic/electrostatic activation of the protonated guanidine, ${ }^{4-6}$ (Fig. 1).

Since conclusions drawn from the cleavage of activated phosphodiesters do not necessarily apply to the cleavage of unactivated phoshodiesters, ${ }^{8}$ it seemed worthwhile to investigate the catalytic activity of $\mathbf{1}$ and $\mathbf{2}$ in the transesterification of a series of diribonucleoside $3^{\prime}, 5^{\prime}$-monophosphates $N p N^{\prime}$, eqn (1), as more appropriate RNA models. The results of such an investigation are reported herein.

${ }^{a}$ Dipartimento di Chimica and IMC - CNR Sezione Meccanismi di Reazione, Università La Sapienza, 00185 Roma, Italy. E-mail: riccardo.salvio@uniroma1.it

${ }^{b}$ Dipartimento di Chimica, Università degli Studi di Parma, Parco Area delle Scienze 17/A, 43124 Parma, Italy

$\dagger$ Electronic supplementary information (ESI) available: HPLC chromatograms for the monitoring of $N p N^{\prime}$ cleavage. See DOI: 10.1039/c4ra05751a

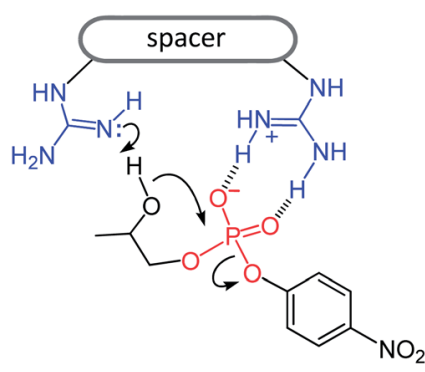

Fig. 1 General-base/general-acid mechanism of HPNP cleavage catalyzed by monoprotonated diguanidino compounds.

\section{Results and discussion}

Catalytic runs were carried out under the same conditions used for the cleavage of HPNP, ${ }^{5}$ namely, $\mathrm{pH} 10.4,10 \mathrm{mM}$ $\mathrm{Me}_{4} \mathrm{NClO}_{4}$, DMSO- $\mathrm{H}_{2} \mathrm{O} 80: 20(\mathrm{v} / \mathrm{v})$, hereafter referred to as $80 \%$ DMSO. The sole difference is the higher temperature $50{ }^{\circ} \mathrm{C}$ rather than $25{ }^{\circ} \mathrm{C}$, dictated by the lower reactivity of diribonucleoside monophosphates compared to HPNP. Solutions of precatalyst $-\mathbf{1} \cdot 2 \mathrm{HCl}$ or $2 \cdot 2 \mathrm{HCl}$ - were exactly half neutralized with 1 mol equiv. of $\mathrm{Me}_{4} \mathrm{NOH}$ to give buffer solutions at $\mathrm{pH} 10.4(\mathrm{pOH} 8.0)^{9}$ that were used for the catalytic experiments. According to the previously reported distribution diagrams of the species as a function of $\mathrm{pH},{ }^{5}$ these solutions contain the maximum concentration of monoprotonated species $1 \mathrm{H}^{+}$or $2 \mathrm{H}^{+}$, amounting to a mole fraction of 0.86 in both cases. The kinetics were monitored by HPLC analysis of aliquots of the reaction mixture withdrawn at time intervals in the early stages of the reaction, as previously described. ${ }^{2 d}$ Initial rates of nucleoside $N^{\prime}$ formation were translated into pseudo-first-order specific rates $k_{\mathrm{obs}}$. 

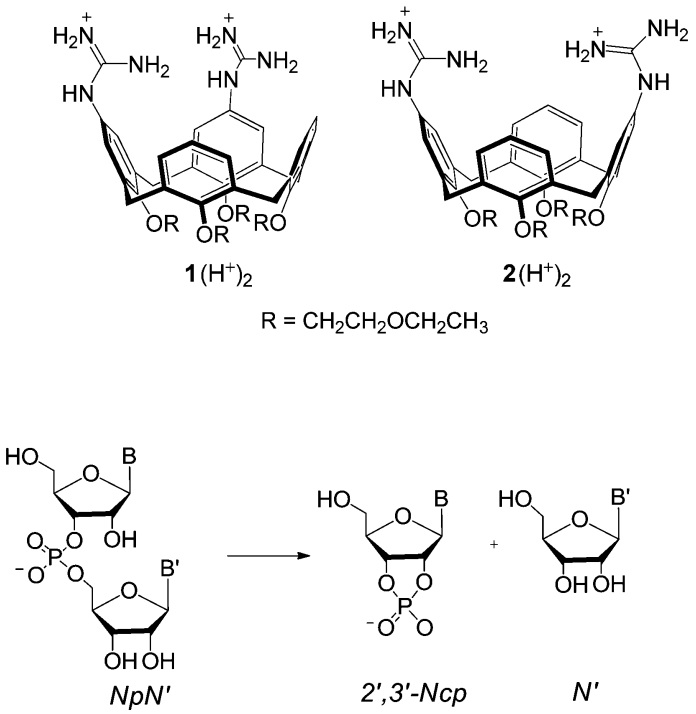

(1)<smiles>CCN1C=Nc2c3c(c(N)nc2=C(N)N1CC(C)(C)C)=NC(=O)NC3=O</smiles>

Typical plots of reaction percentage $v s$. time related to the cleavage of GpU catalyzed by $\mathbf{1}$ are shown in Fig. 2a. The diagram of $k_{\text {obs }} v s$. buffer concentration (Fig. 2b) shows a good adherence of data points to a straight line with zero intercept, and this indicates (i) that the contribution of background hydrolysis to the overall rate is negligibly small and (ii) that the catalyst works under subsaturating conditions, i.e. binding of the catalyst to the substrate is too low to affect the kinetics in the investigated concentration range $\left(K<25 \mathrm{M}^{-1}\right)$. An analogous result was obtained in our previous studies of the cleavage of HPNP. ${ }^{5,6}$ This finding not only confirms that in the reactant state binding of guanidinium to the negatively charged phosphate moiety is insignificant, but also indicates that any possible stabilizing interaction between guanidine/guanidinium units and nucleobases $B$ and $B^{\prime}$ is negligibly small.

Having established that the kinetics of the reaction of $\mathrm{GpU}$ catalyzed by 1 were not complicated by a pre-association equilibrium, the whole set of catalytic runs listed in Table 1 were carried out using a fixed precatalyst concentration of $2.0 \mathrm{mM}$, under the assumption that subsaturating conditions applies to all runs. Table 1 shows that both catalysts effectively cleave all of the investigated substrates, with a marked preference for $\mathrm{GpU}$, GpG and UpU (entries 1-3), while the reactions of the remaining substrates experience a much lower nucleobase selectivity (entries 4-8). The finding that UpG is much less reactive than GpU, and that both ApG and GpA react slowly, clearly indicates that catalytic efficiency depends in a very critical way on the identity of both nucleobases $B$ and $B^{\prime}$. Interestingly, literature data on the cleavage of diribonucleoside monophosphates catalyzed by di- and trinuclear metal complexes ${ }^{2 d, 10}$ show that in many cases in which high nucleobase selectivity is observed, at least one of the two nucleobases is either uracyl or guanine..$^{2 d, 10 a, e-g}$ In the latter cases enhanced rates of cleavage have been ascribed
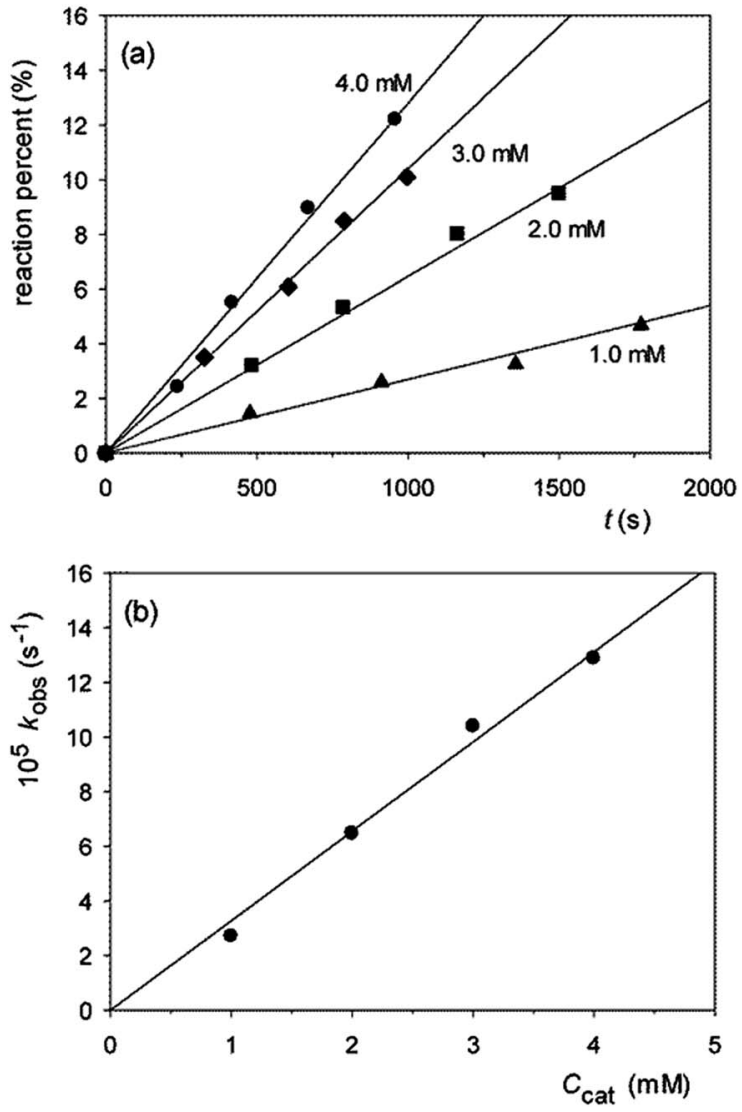

Fig. 2 Cleavage of $0.10 \mathrm{mM} \mathrm{GpU}$ catalyzed by $1.0-4.0 \mathrm{mM} 1(80 \%$ DMSO, $\mathrm{pH} 10.4,10 \mathrm{mM} \mathrm{Me}_{4} \mathrm{NClO}_{4}, 50.0^{\circ} \mathrm{C}$ ). (a) Reaction percent vs. time, for experiments carried out at the given catalyst concentration. (b) Plot of $k_{\mathrm{obs}} v s$. total catalyst concentration $c_{\text {cat. }}$

to a pre-association mechanism, supported by spectroscopic $\mathrm{c}^{\mathbf{1 0 f}, \boldsymbol{g}}$ and kinetic ${ }^{10 a, e-g}$ data, in which the deprotonated amidic $\mathrm{N}-\mathrm{H}$ of a uracyl or guanine serves as a site for anchoring to a ligated zinc(II) or copper(II) unit of the catalyst. In the present work GpU, GpG, and UpU turn out to be the most reactive substrates in the lot, but

Table 1 Cleavage of diribonucleoside $3^{\prime}, 5^{\prime}$-monophosphates $N p N^{\prime}$ in the presence of guanidinocalix[4]arenes 1 and $2^{a, b}$

\begin{tabular}{|c|c|c|c|c|c|c|}
\hline \multirow[b]{2}{*}{ Entry } & \multirow[b]{2}{*}{$N p N^{\prime}$} & \multicolumn{2}{|l|}{1 (1,2-vicinal) } & \multicolumn{2}{|l|}{2 (1,3-distal) } & \multirow[b]{2}{*}{$k_{\text {vicinal }} / k_{\text {distal }}^{c}$} \\
\hline & & $10^{6} \times k_{\mathrm{obs}}\left(\mathrm{s}^{-1}\right)$ & $k_{\text {rel }}$ & $10^{6} \times k_{\mathrm{obs}}\left(\mathrm{s}^{-1}\right)$ & $k_{\text {rel }}$ & \\
\hline 1 & GpU & 65 & 88 & 24 & 38 & 2.7 \\
\hline 2 & GpG & 62 & 84 & 14 & 22 & 4.4 \\
\hline 3 & UpU & 14 & 19 & 9.8 & 16 & 1.4 \\
\hline 4 & ApG & 2.4 & 3.2 & 1.3 & 2.1 & 1.8 \\
\hline 5 & GpA & 1.0 & 1.3 & 1.3 & 2.1 & 0.8 \\
\hline 6 & $\mathrm{CpC}$ & 2.2 & 3.0 & 1.2 & 1.9 & 1.7 \\
\hline 7 & $\mathrm{CpA}$ & 0.74 & 1.0 & 0.92 & 1.5 & 0.8 \\
\hline 8 & UpG & 1.9 & 2.6 & 0.63 & 1.0 & 3.0 \\
\hline
\end{tabular}

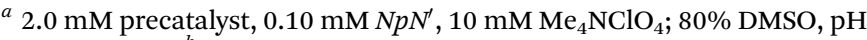
$10.4,50.0{ }^{\circ} \mathrm{C} .{ }^{b}$ Pseudo-first order specific rates $k_{\text {obs }}$ calculated from initial rates of HPLC monitored nucleoside liberation. Error limits on the order of $\pm 10 \%$. ${ }^{c}$ For HPNP $k_{\text {vicinal }} / k_{\text {distal }}=0.5$, see ref. 5 . 
in the absence of metal ions, deprotonation of the amidic $\mathrm{N}-\mathrm{H}$ bond is unlikely at the $\mathrm{pH}$ value of our measurements. No significant interaction between substrate and catalyst occurs in the reactant state, as clearly demonstrated by the kinetics (Fig. 2b). As suggested by CPK molecular models, interaction between the relatively large and conformationally mobile catalyst and substrate molecules generates a large number of potentially attractive and repulsive secondary interactions involving distal part structures of the reactants. In the lack of information of spectroscopic nature, a rational interpretation of the role played by uracyl and guanine bases appears to be out of reach.

There is a definite tendency for the 1,2-vicinal regioisomer 1 to be a better catalyst than its 1,3-distal regioisomer 2 in the reaction of most substrates, but the range of $k_{\text {vicinal }} / k_{\text {distal }}$ ratios (Table 1) is within a factor of 5 . Modest inversions are observed for the reaction of $\mathrm{GpA}$ and $\mathrm{CpA}$ (entries 5 and 7), for which the 1,3-distal regioisomer is a slightly better catalyst, as it is for the cleavage of HPNP, ${ }^{5}$ for which $k_{\text {vicinal }} / k_{\text {distal }}=0.5$.

Interestingly, the $k_{\text {vicinal }} / k_{\text {distal }}$ ratio for the cleavage of CpA, UpU, and HPNP catalyzed by bimetallic complexes $3-\mathrm{Cu}_{2}$ and 4$\mathrm{Cu}_{2}\left(\mathrm{H}_{2} \mathrm{O}, \mathrm{pH} 7.0\right)$ are $2.8,114$, and 28 , in the given order. ${ }^{2 d}$ Although the comparison is based on a limited set of substrates, it appears that the relative position of the two catalytic units in the diguanidinocalix[4]arenes has but a moderate influence on catalytic efficiency. This suggests the existence of a certain degree of flexibility in transition states in which contacts between catalyst and substrate are primarily provided by proton bridges (Fig. 1). In contrast, the marked preference exhibited by UpU and HPNP for the 1,2-vicinal catalyst $3-\mathrm{Cu}_{2}$ is most likely ascribable to the more stringent geometrical requirements of coordinative bonds to copper(II) involved in the double Lewis acid activation. $^{2 d}$

In order to compare the catalytic efficiency of $\mathbf{1}$ and $\mathbf{2}$ in the cleavage of diribonucleoside monophosphates $v s$. HPNP, catalytic rates relative to background $\left(k_{\mathrm{obs}} / k_{\mathrm{bg}}\right)$ are required. Initial rates of the hydroxide catalyzed cleavage of $\mathrm{CpA}$ and $\mathrm{GpU}$, measured in the presence of $1.0 \mathrm{mM} \mathrm{Me}{ }_{4} \mathrm{NOH}$ ( $\mathrm{pH} 15.4$ ), gave $k_{\mathrm{bg}}$ values of $5.7 \times 10^{-5} \mathrm{~s}^{-1}$ and $9.4 \times 10^{-5} \mathrm{~s}^{-1}$, respectively. These values were extrapolated to $\mathrm{pH} 10.4$ under the assumption that the reaction is specific base catalyzed, on the analogy of the corresponding reaction of HPNP, that was found to be strictly first order in hydroxide concentration in the $\mathrm{pH}$ range 9.3-13.0. ${ }^{5}$ The results listed in Table 2 show that both 1 and 2 are from 1 to 2 orders of magnitude more effective in the cleavage of CpA and GpU than in the cleavage of HPNP. Thus, replacement of a good leaving group with a bad leaving group has a favorable effect on catalytic efficiency.

Both an associative two step $\left(\mathrm{A}_{\mathrm{N}}+\mathrm{D}_{\mathrm{N}}\right)$ mechanism involving a pentavalent phosphorane dianion intermediate, and a concerted $\left(\mathrm{A}_{N} \mathrm{D}_{\mathrm{N}}\right)$ mechanism in which no intermediate is involved, are likely possibilities for the hydrolysis of phosphate diesters. $^{2 o}$ The reactions of phosphate diesters with good leaving groups are believed to proceed via a one step $\left(\mathrm{A}_{\mathrm{N}} \mathrm{D}_{\mathrm{N}}\right)$ mechanism, ${ }^{11}$ also labeled as $\mathrm{S}_{\mathrm{N}} 2(\mathrm{P}) .{ }^{12}$ When the leaving group is poor the question of mechanism is still under debate, but there is little doubt that upon replacement of a good leaving
Table 2 Cleavage of $\mathrm{CpA}$, GpU, and HPNP catalyzed by 1 and 2 in $80 \%$ DMSO, $\mathrm{pH}$ 10.4. Catalytic rate enhancements relative to background, $k_{\mathrm{obs}} / k_{\mathrm{bg}}$

\begin{tabular}{llll}
\hline Catalyst & $\mathrm{CpA}^{a, b}$ & $\mathrm{GpU}^{a, c}$ & $\mathrm{HPNP}^{d}$ \\
\hline 1 & $1.3 \times 10^{3}$ & $6.6 \times 10^{4}$ & $1.4 \times 10^{2}$ \\
2 & $1.6 \times 10^{3}$ & $2.4 \times 10^{4}$ & $2.9 \times 10^{2}$
\end{tabular}

${ }^{a}$ At $50.0{ }^{\circ} \mathrm{C} . k_{\mathrm{obs}}$ values from Table $1 .{ }^{b} k_{\mathrm{bg}}=(5.7 \pm 0.4) \times 10^{-10} \mathrm{~s}^{-1}$. ${ }^{c} k_{\mathrm{bg}}=(9.8 \pm 0.4) \times 10^{-10} \mathrm{~s}^{-1} \cdot{ }^{d}$ At $25.0{ }^{\circ} \mathrm{C}$; calculated from data in ref. 5 .

group with a poor one the transition state becomes tighter, i.e. more associative in character and, consequently, bears a close resemblance to a pentavalent phosphorane dianion, independent of whether the mechanism is $\left(A_{N}+D_{N}\right)$ or $\left(A_{N} D_{N}\right)$. Accordingly, the larger rate enhancements experienced by the reactions of $N p N^{\prime}$ substrates are understood as arising from a stronger electrophilic/electrostatic stabilization of the transition state by the guanidinium unit of the bifunctional catalysts.

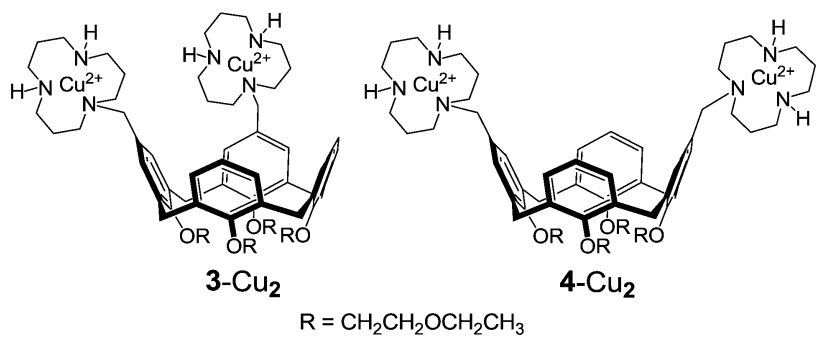

As a final comment, the close similarity of $k_{\mathrm{bg}}$ values measured for $\mathrm{CpA}$ and $\mathrm{GpU}$ is consistent with the fact that rates of background cleavage of the phosphodiester bond of diribonucleoside monophosphates are affected by nucleobase identity to a moderate extent. ${ }^{8 a, 13}$ It seems therefore reasonable to assume that the $k_{\mathrm{bg}}$ values actually measured for two members of the series are representative of the whole series and, consequently, that rate enhancements as high as $10^{3}-10^{5}$ characterize the performances of catalysts $\mathbf{1}$ and $\mathbf{2}$ in the cleavage of the eight $N p N^{\prime}$ investigated substrates. These values are comparable in magnitude with rate accelerations reported for artificial di- and trimetallic phosphodiesterases. ${ }^{2 d, 2 j, 10,14}$

\section{Conclusions}

To sum up, we have shown that diguanidinocalix[4]arenes 1 and 2 catalyze the cleavage of diribonucleoside monophosphates much more efficiently than the cleavage of HPNP, most likely on account of a greater negative charge development on the nonbridging oxygen atoms in the transition state of the reaction of phosphodiesters with bad leaving groups. To the best of our knowledge, reactivity data related to the cleavage of a series of diribonucleoside monophosphates catalyzed by nonmetallic synthetic catalysts are here presented for the first time. When combined with data from previous studies, the data reported in this work reinforce the notion that cone-calix[4]arenes are useful platforms for the design of efficient bifunctional catalysts. ${ }^{15}$ The 
good catalytic efficiency and selectivity of the diguanidino derivatives described in this work encourages further studies in the cleavage of RNA polynucleotides.

\section{Experimental}

\section{Instruments and general methods}

Materials. DMSO, purged 30 min with argon, and mQ water were used in the preparation of 80\% DMSO. Calixarenes 1 and 2 were available from previous investigations. ${ }^{5}$ Diribonucleoside $3^{\prime}, 5^{\prime}$-monophosphates UpU, GpG, and ApG were purchased from Sigma-Aldrich, while UpG, CpC, GpA, GpU, and CpA were from Dharmacon Research (Lafayette, CO). Pure samples of $N p N^{\prime}$ and their aqueous solutions were stored at $-20^{\circ} \mathrm{C}$.

Warning! Care was taken when handling tetramethylammonium perchlorate because it is potentially explosive. No accident occurred in the course of the present work.

Kinetic measurements. Cleavage of diribonucleoside $3^{\prime}, 5^{\prime}$ monophosphates $N p N^{\prime}$ was monitored by HPLC analyses of aliquots of the reaction mixture withdrawn at appropriate time intervals. Reactions were carried out at $50.0^{\circ} \mathrm{C}$, $\mathrm{pH} 10.4$, on 0.10 $\mathrm{mM} N p N^{\prime}$, and 1-4 mM catalyst solutions in $80 \%$ DMSO, $10 \mathrm{mM}$ $\mathrm{Me}_{4} \mathrm{NClO}_{4}$. The $\mathrm{pH}$ of the solution was measured by a microglass $\mathrm{pH}$ electrode. Experimental details and procedures for the electrode calibration were as previously reported. ${ }^{5}$ In a typical experiment, half-neutralization of precatalyst was carried out by addition of a solution of $\mathrm{Me}_{4} \mathrm{NOH}$ in $80 \%$ DMSO until pH 10.4 was reached. The mixture was thermostated at $50.0{ }^{\circ} \mathrm{C}$ for 30 min and the reaction was started by addition of a calculated small volume of a $5.0 \mathrm{mM}$ solution of $N p N^{\prime}$ in water. At proper time intervals, aliquots $(80 \mu \mathrm{L})$ of the reaction mixture were withdrawn and quenched with $80 \mu \mathrm{L}$ of a $10 \mathrm{mM}$ solution of $\mathrm{HClO}_{4}$ in $80 \%$ DMSO. After addition of $p$-hydroxybenzoic acid (internal standard) in $80 \%$ DMSO, the solution was filtered and subjected to HPLC analysis by elution with $\mathrm{H}_{2} \mathrm{O}(0.1 \%$ trifluoroacetic acid)/MeCN, linear gradient from $100: 0$ to $85: 15$

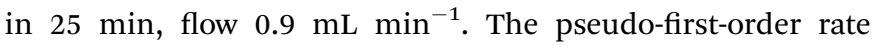
constant for the hydroxide catalyzed cleavage of $\mathrm{CpA}$ and $\mathrm{GpU}$ was measured at $50.0{ }^{\circ} \mathrm{C}$ in the presence of $1.0 \mathrm{mM} \mathrm{Me}{ }_{4} \mathrm{NOH}$ ( $p \mathrm{OH}$ 3.0), $10 \mathrm{mM} \mathrm{Me}_{4} \mathrm{NClO}_{4}$, by HPLC monitoring of the nucleoside liberation (initial rate method).

\section{Acknowledgements}

Thanks are due to the Ministero dell'Istruzione e dell'Università e della Ricerca (MIUR, PRIN 2010 JMAZML-006) and the Consiglio Nazionale delle Ricerche (CNR) for financial support.

\section{Notes and references}

1 R. Wolfenden, Chem. Rev., 2006, 106, 3379.

2 (a) P. Molenveld, J. F. J. Engbersen and D. N. Reinhoudt, Chem. Soc. Rev., 2000, 29, 75; (b) J. R. Morrow and O. Iranzo, Curr. Opin. Chem. Biol., 2004, 8, 192; (c) R. Cacciapaglia, A. Casnati, L. Mandolini, D. N. Reinhoudt, R. Salvio, A. Sartori and R. Ungaro, J. Org. Chem., 2005, 70, 624; (d) R. Cacciapaglia, A. Casnati, L. Mandolini,
D. N. Reinhoudt, R. Salvio, A. Sartori and R. Ungaro, J. Am. Chem. Soc., 2006, 128, 12322; (e) A. Scarso, G. Zaupa, F. B. Houillon, L. J. Prins and P. Scrimin, J. Org. Chem., 2007, 72, 376; (f) R. Cacciapaglia, A. Casnati, L. Mandolini, A. Peracchi, D. N. Reinhoudt, R. Salvio, A. Sartori and R. Ungaro, J. Am. Chem. Soc., 2007, 129, 12512; $(g)$ T.-S. A. Tseng and J. N. Burstyn, Chem. Commun., 2008, 6209; (h) R. Bonomi, F. Selvestrel, V. Lombardo, C. Sissi, S. Polizzi, F. Mancin, U. Tonellato and P. Scrimin, J. Am. Chem. Soc., 2008, 130, 15744; (i) C. Bazzicalupi, A. Bencini, C. Bonaccini, C. Giorgi, P. Gratteri, S. Moro, M. Palumbo, A. Simionato, J. Sgrignani, C. Sissi and B. Valtancoli, Inorg. Chem., 2008, 47, 5473; (j) K. Nwe, C. M. Andolina and J. R. Morrow, J. Am. Chem. Soc., 2008, 130, 14861; (k) H. Katada and M. Komiyama, ChemBioChem, 2009, 10, 1279; (l) M. F. Mohamed and R. S. Brown, J. Org. Chem., 2010, 75, 8471; $(m)$ R. Salvio, R. Cacciapaglia and L. Mandolini, J. Org. Chem., 2011, 76, 5438; (n) H. Lönnberg, Org. Biomol. Chem., 2011, 9, 1687; (o) F. Mancin, P. Scrimin and P. Tecilla, Chem. Commun., 2012, 48, 5545; (p) M. Raynal, P. Ballester, A. Vidal-Ferran and P. W. van Leeuwen, Chem. Soc. Rev., 2014, 43, 1734.

3 (a) A. M. Piatek, M. Gray and E. V. Anslyn, J. Am. Chem. Soc., 2004, 126, 9878; (b) U. Scheffer, A. Strick, V. Ludwig, S. Peter, E. Kalden and M. W. Göbel, J. Am. Chem. Soc., 2005, 127, 2211; (c) C. Gnaccarini, S. Peter, U. Scheffer, S. Vonhoff, S. Klussmann and M. W. Göbel, J. Am. Chem. Soc., 2006, 128, 8063; (d) N. J. V. Lindgren, J. R. Lars Geiger, C. Schmuck and L. Baltzer, Angew. Chem., Int. Ed., 2009, 48, 6722; (e) J. M. Thomas, J.-K. Yoon and D. M. Perrin, J. Am. Chem. Soc., 2009, 131, 5648; (f) M. Hollenstein, C. J. Hipolito, C. H. Lam and D. M. Perrin, ChemBioChem, 2009, 10, 1988; (g) R. Salvio, A. Casnati, L. Mandolini, F. Sansone and R. Ungaro, Org. Biomol. Chem., 2012, 10, 8941; (h) R. Salvio and A. Cincotti, RSC Adv., 2014, 4, 28678. 4 D. O. Corona-Martinez, O. Taran and A. K. Yatsimirsky, Org. Biomol. Chem., 2010, 8, 873.

5 L. Baldini, R. Cacciapaglia, A. Casnati, L. Mandolini, R. Salvio, F. Sansone and R. Ungaro, J. Org. Chem., 2012, 77, 3381.

6 R. Salvio, L. Mandolini and C. Savelli, J. Org. Chem., 2013, 78, 7259.

7 (a) A. Demesmaeker, R. Haner, P. Martin and H. E. Moser, Acc. Chem. Res., 1995, 28, 366; (b) B. N. Trawick, A. T. Daniher and J. K. Bashkin, Chem. Rev., 1998, 98, 939.

8 (a) M. Oivanen, S. Kuusela and H. Lönnberg, Chem. Rev., 1998, 98, 961; (b) K. Worm, F. Chu, K. Matsumoto, M. D. Best, V. Lynch and E. V. Anslyn, Chem.-Eur. J., 2003, 9, 741.

9 The $\mathrm{p} K_{\mathrm{w}}$ for water autoprotolysis in $80 \%$ DMSO is 18.4 (M. M. Kreevoy and E. H. Baughman, J. Phys. Chem., 1974, 78, 421). This implies that the $\mathrm{pH}$ value of a neutral solution is 9.2 .

10 (a) P. Molenveld, J. F. J. Engbersen and D. N. Reinhoudt, Angew. Chem., Int. Ed., 1999, 38, 3189; (b) S. Liu and A. D. Hamilton, Chem. Commun., 1999, 587; (c) M. Komiyama, S. Kina, K. Matsumara, J. Sumaoka, 
S. Tobey, V. M. Lynch and E. Anslyn, J. Am. Chem. Soc., 2002, 124, 13731; (d) M. Yashiro, H. Kaneiwa, K. Onaka and M. Komiyama, Dalton Trans., 2004, 605; (e) Q. Wang, S. Mikkola and H. Lönnberg, Chem. Biodiversity, 2004, 1, 1316; $(f)$ Q. Wang and H. Lönnberg, J. Am. Chem. Soc., 2006, 128, 10716; $(g)$ Q. Wang, E. Leino, A. Jancsó, I. Szilágyi, T. Gajda, E. Hietamäki and H. Lönnberg, ChemBioChem, 2008, 9, 1739.

11 W. W. Cleland and A. C. Hengge, Chem. Rev., 2006, 106, 3252.
12 A. J. Kirby, M. Medeiros, J. R. Mora, P. S. M. Oliveira, A. Amer, N. H. Williams and F. Nome, J. Org. Chem., 2013, 78, 1343.

13 M. Komiyama, Carbohydr. Res., 1989, $192,97$.

14 (a) N. H. Williams, B. Takasaki, M. Wall and J. Chin, Acc. Chem. Res., 1999, 32, 485; (b) H. Linjalahti, G. Feng, J. C. Mareque-Rivas, S. Mikkola and N. H. Williams, J. Am. Chem. Soc., 2008, 130, 4232.

15 R. Cacciapaglia, S. Di Stefano, L. Mandolini and R. Salvio, Supramol. Chem., 2013, 25, 537, and references cited therein. 